\title{
Sex-specific growth effects in protogynous hermaphrodites
}

\author{
Philip L. Munday, Alyson L. Hodges, J. Howard Choat, and Nick Gust
}

\begin{abstract}
We demonstrate sex-specific decoupling of otolith growth and somatic growth in two species of protogynous parrotfishes, Scarus frenatus and Chlorurus sordidus. Otoliths of both species increased in size consistently through life, even though somatic growth rate decreased with age (age effect). Furthermore, in $S$. frenatus, otoliths from terminal males were smaller than otoliths from females, despite males being larger than females of the same age. This demonstrates the presence of a sex-specific growth effect, where otoliths of fast-growing individuals (males) are smaller than otoliths of slow-growing individuals (females). The sex-specific growth effect for $S$. frenatus was most pronounced during the early life history, which suggests that only the fastest-growing females change sex to male. A sex-specific growth effect was also evident in C. sordidus, although it was not statistically significant because of greater variation in the otolith size of terminal males of this species. Our results demonstrate that the relationship between otolith and somatic growth can vary dramatically between the sexes. This will make it difficult to back-calculate size at age in protogynous species, or to conduct sex-specific back-calculations in gonochoristic species, unless the precise relationship between otolith and somatic growth is known for each sex.
\end{abstract}

Résumé : Nous avons démontré l'existence d'un découplage spécifique au sexe entre la croissance des otolithes et celle du corps chez deux espèces de poissons perroquets protogynes, Scarus frenatus et Chlorurus sordidus. Les otolithes des deux espèces croissent continuellement en taille tout au cours de la vie, bien que le taux de croissance somatique décline avec l'âge (effet de l'âge). De plus, les otolithes des mâles terminaux de $S$. frenatus sont plus petits que ceux des femelles, bien que les mâles soient plus grands que les femelles au même âge. Il y a donc un effet de croissance spécifique au sexe dans lequel les otolithes des individus à croissance rapide (les mâles) sont plus petits que ceux des individus à croissance lente (femelles). Cet effet de croissance spécifique au sexe chez $S$. frenatus se manifeste plus intensément durant la première partie du cycle biologique, ce qui laisse croire que seules les femelles ayant la croissance la plus rapide se transforment en mâles. Il existe aussi un effet de croissance spécifique au sexe chez C. sordidus, bien qu'il ne soit pas statistiquement significatif à cause de la variation plus grande de la taille des otolithes des mâles terminaux chez cette espèce. Nos résultats démontrent que la relation entre la croissance des otolithes et celle du corps peut varier considérablement d'après le sexe. Il est donc difficile de déterminer par rétrocalcul la taille en fonction de l'âge chez les espèces protogynes et de faire des rétrocalculs spécifiques au sexe chez les espèces à sexes séparés, à moins que la relation exacte entre la croissance des otolithes et celle du corps ne soit connue pour chacun des sexes.

[Traduit par la Rédaction]

\section{Introduction}

Back-calculation is commonly used to estimate the size of fish at an earlier age by making use of regular marks that are deposited in bony structures, such as otolith or scales. The principal assumption of most back-calculation models is a proportional relationship between otolith growth and somatic growth. Where this assumption holds, and where otolith increment marks are deposited on a known time scale (usually daily or annually), it is possible to use work back-

Received 17 February 2004. Accepted 17 March 2004. Published on the NRC Research Press Web site at http://cjfas.nrc.ca on 6 April 2004.

$\mathrm{J} 17973$

P.L. Munday, ${ }^{1,2}$ A.L. Hodges, and J.H. Choat. School of Marine Biology and Aquaculture, James Cook University, Townsville, QLD, Australia, 4811.

N. Gust. School of Marine Biology and Aquaculture, James Cook University, Townsville, QLD, Australia, 4811, and National Institute of Water and Atmospheric Research, P.O. Box 8602, 10 Kyle Street, Christchurch, New Zealand.

${ }^{1}$ Corresponding author (e-mail: philip.munday@jcu.edu.au).

${ }^{2}$ Present address: Department of Ecology, Evolution and Marine Biology (Warner Lab), University of California Santa Barbara, Santa Barbara, CA 93109, U.S.A. 
wards from an individuals length and otolith size at capture to estimate its length at some earlier time (Francis 1990).

It has been known for some time that somatic and otolith growth are not always tightly coupled (Campana 1990). The usual manifestation of this mismatch between otolith growth and somatic growth is the so-called "growth effect", where otoliths from fast-growing individuals are smaller than otoliths from slow-growing individuals (Reznick et al. 1989). An additional problem is the "age effect", where otoliths increase in size through life, even though somatic growth may vary, or even stop (Secor and Dean 1992). A number of modifications have been made to standard back-calculation models to deal with growth (e.g., Sirois et al. 1998) and age effects (e.g., Morita and Matsuishi 2001); however, these models generally assume that any growth or age effects are similar for both sexes.

There is increasing evidence that growth rates during the early life history can influence primary sex determination (Francis and Barlow 1993) and the expression of alternative male reproductive behaviours (Metcalfe et al. 1989) in fishes. Early life history growth rates might also influence patterns of sex change in hermaphroditic species, especially where sex change is socially controlled and only the largest individual(s) in a social group or cohort change sex (Francis 1992). Back-calculation of size at age could be used to estimate sex-specific growth trajectories in fishes and, consequently, might be a useful tool for testing the relationship between growth rate and sex determination in gonochoristic (species with fixed sexes) and hermaphroditic species. However, the use of back-calculation for this purpose will depend on the presence of a predictable relationship between otolith and somatic growth for both sexes.

To test for sex-specific growth or age effects, we compared patterns of otolith growth of males and females in two protogynous parrotfishes, Scarus frenatus and Chlorurus sordidus. These species are useful for testing the sex-specific relationship between otolith growth and somatic growth because terminal males are larger than females of the same age (Choat et al. 1996). If otolith and somatic growth were closely coupled, then we would expect to see a divergence in cumulative otolith size in males and females, corresponding with the differences in size between the sexes. In contrast, if a growth effect was present, we might expect males to have smaller otoliths than females. Finally, if an age effect was present, we might expect the otoliths of males and females to continue growing, even though somatic growth declines with age.

\section{Methods}

\section{Study species}

Scarus frenatus is a monandric, protogynous hermaphroditic species in which all males are sex-changed females. A monandric mode of sexual development is useful for comparing sex-specific patterns of otolith growth because there is only one developmental pathway for males. On the Northern Great Barrier Reef, all female S. frenatus are a drab, initial-phase colouration and all males are a bright, terminal-phase colouration. The mean age of sex change in the study population is 4.5 years (Gust 2004).
Chlorurus sordidus is a diandric, protogynous hermaphroditic species with two developmental pathways for males. Some individuals are male from a very young age (primary males), whereas others are sex-changed females (secondary males). The brightly-coloured terminal-phase males can be either secondary males or primary males that have transformed to the bright terminal phase. Whether a terminal phase $C$. sordidus arose from a female or a primary male could not be determined. However, this did not preclude a comparison of otoliths from terminal males and females because terminal males are larger than females of the same age, regardless of whether they were originally females or primary males. Furthermore, primary males made up less than 3\% of the sample population (Gust 2004); therefore, very few of the terminal males used in our analysis would have been derived from primary males. All initial-phase C. sordidus used in the analysis were female. The mean age of sex change in the study population is 3.5 years (Gust 2004).

\section{Collection, otolith preparation, and analysis}

Specimens were collected by spear fishing from the fringing reef at Lizard Island, North Direction Island, and South Direction Island on the Northern Great Barrier Reef, Australia (Gust et al. 2002). The standard length and developmental phase (initial or terminal) were recorded for each fish. Sex was determined by histological inspection of the gonads (Gust 2004). Sagittal otoliths were removed from each fish, cleaned, mounted on a glass slide with thermoplastic glue, ground down to the core with $\mathrm{P} 400$-grit abrasive paper, and then polished with P800-grit abrasive paper.

Otolith increments have been validated to be annular in C. sordidus and S. frenatus (Choat et al. 1996). Age was estimated by counting the number of annual increments in each otolith for $363 \mathrm{~S}$. frenatus (221 females and 142 males) and 261 C. sordidus (190 females and 71 males) randomly selected from a wide size range of fish.

Otolith radius in yearly increments (cumulative otolith radius) was estimated by measuring the distance from the core to the distal edge of the dark section of each annular ring for 25 S. frenatus (12 females, 13 terminal males) and 29 C. sordidus (14 females, 15 terminal males). Measurements were taken on a straight transect at $52^{\circ}$ to the horizontal on the dorsal side of the sulcus. An angle of $52^{\circ}$ was chosen because annular rings were clearest along this axis for most otoliths. Individuals in the older age classes at capture (6-16 years for $S$. frenatus and 4-9 years for $C$. sordidus) were selected for this analysis so that $(i)$ sex-specific patterns of otolith growth could be compared over a large proportion of the life span and (ii) sex change would be complete and we could compare otolith and somatic growth of females that change sex to male (called males for simplicity) with females that did not change sex. Otolith measurements were conducted using a $40 \times$ compound microscope connected to a video camera and Optimas digital image analysis software (Media Cybernetics, Silver Spring, MD 20910).

\section{Data analysis}

The relationship between (i) length and age, (ii) cumulative otolith radius and age, and (iii) otolith radius and size at 
capture was plotted separately for males and females of each species. The comparison between these plots allowed us to assess the relationship between the somatic growth pattern and otolith growth through time. Repeated-measures analysis of variance (RM-ANOVA) was then used to statistically compare cumulative otolith width at each age for males and females. Analysis of cumulative otolith radius was not extended to the oldest age classes (14-16 years for $S$. frenatus and 8-9 years for $C$. sordidus) because there were insufficient individuals in these age classes to conduct statistical analyses. The general linear model function in Statistica 6.0 (StatSoft, Inc., Tulsa, Okla.) was used for all analyses.

\section{Results and discussion}

Scarus frenatus exhibited an asymptotic pattern of somatic growth (Fig. 1a). In contrast, the otoliths of both sexes increased in diameter at a relatively consistent rate throughout life (Fig. 1b). The mismatch between somatic and otolith growth patterns indicates the presence of an age effect, where otoliths grow at a constant rate despite a declining somatic growth rate. In addition, cumulative otolith radius of males was smaller than that of females throughout most of the life span (Fig. 1b), even though males were larger than females of the same age (Fig. 1a). Therefore, there was a sex-specific growth effect in this species. The otoliths of females that became male were initially smaller than those of other females, but increased in size at a significantly greater rate than the otoliths of females that did not change sex (Fig. 1b; Table 1, significant interaction between age and sex). This is confirmed by a significant main effect (sex: $F_{[1,20]}=4.65, P=0.04$ ) when just the first 8 years of life were considered and the convergence of otolith sizes from males and females at about 11-12 years of age (Fig. 1b). The growth effect is also evident in the otolith size - fish size relationship at the time of capture, with males being larger than females for a given otolith radius (Fig. 1c). Growth effects, where the otoliths of fast-growing individuals are smaller than the otoliths of slow-growing individuals, have been demonstrated previously (Campana 1990; Secor and Dean 1992), but to our knowledge, this is the first description of a sex-specific growth effect.

The growth effect in $C$. frenatus is useful for investigating the relationship between growth rate and patterns of sex change in this species. The smaller size of otoliths from males before the mean age of sex change (4.5 years) suggests that females that became males might have been growing faster than other females before the age of sex change. This is consistent with the observation that sex change is socially mediated in many protogynous reef fishes, with the largest female in a social group becoming male and then suppressing sex change in subordinate females (Francis 1992). Furthermore, the fact that the otoliths of females that changed sex to male were already smaller than the otoliths of other females at age 1 (Fig. $1 b$ ) suggests that differences in growth during the first year of growth could influence which individuals ultimately become terminal males.

Chlorurus sordidus also exhibited an asymptotic pattern of somatic growth (Fig. 1d) that contrasted with a relatively consistent increase in otolith diameter throughout life (Fig. 1e). Thus an age effect was present in $C$. sordidus, just
Table 1. Repeated-measures analysis of variance (RM-ANOVA) comparing cumulative otolith radius between males and females for Scarus frenatus (13 years) and Chlorurus sordidus (7 years).

\begin{tabular}{|c|c|c|c|c|}
\hline Source of variation & Mean square & df & $F$ & $P$ \\
\hline \multicolumn{5}{|l|}{ S. frenatus } \\
\hline \multicolumn{5}{|l|}{ Between subjects } \\
\hline Sex & 17447 & 1 & 0.58 & 0.46 \\
\hline Error & 30050 & 12 & & \\
\hline \multicolumn{5}{|l|}{ Within subjects } \\
\hline Age & 594781 & 12 & 1009.3 & $<0.001$ \\
\hline Age $\times$ sex & 9153 & 13 & 2.1 & 0.02 \\
\hline Error & 2620 & 144 & & \\
\hline \multicolumn{5}{|l|}{ C. sordidus } \\
\hline \multicolumn{5}{|l|}{ Between subjects } \\
\hline Sex & 191738 & 1 & 3.14 & 0.11 \\
\hline Error & 6109 & 9 & & \\
\hline \multicolumn{5}{|l|}{ Within subjects } \\
\hline Age & 232542 & 6 & 222.6 & $<0.001$ \\
\hline Age $\times$ sex & 1027 & 6 & 0.98 & 0.45 \\
\hline Error & 1045 & 52 & & \\
\hline
\end{tabular}

as it was in $S$. frenatus. At the time of capture, terminal males were larger than females for a given otolith radius (Fig. 1f). The mean cumulative otolith radius of terminal males was always smaller than females (Fig. 1e); however, the effect was not statistically significant (Table 1). This suggests that a sex-specific growth effect is present in $S$. sordidus, but is not as strong as that seen in $S$. frenatus. Alternatively, females that became males may have always had relatively small otoliths compared with other females. The lack of statistical significance in otolith size between terminal male and female $C$. sordidus appears to be driven by greater variation in otolith size at age for this species compared with $S$. frenatus, especially for males (Figs. $1 b$ and 1e). Additional variation in otolith size might result from differences in the mating system between these two species. Scarus frenatus is strictly haremic and all males are sex-changed females. In contrast, $C$. sordidus is often observed to group spawn and some terminal males are primary males that have transformed to terminal male status (Choat et al. 1996; Gust 2004). The presence in our sample of a small number of terminal males that originated from primary males will likely introduce more variation into the relationship between otolith growth and somatic growth of terminal males. Furthermore, the occurrence of both group and pair spawning in the natural population of $C$. sordidus might increase the size range over which females become terminal males. In general, the lack of a significant difference in cumulative otolith radius for males and females of $C$. sordidus, despite males being bigger than females of the same age, means that sex-specific differences in growth rate were not recorded in the otoliths in a way that is easily interpreted.

Otolith back-calculation could be useful for estimating the size of male and female fishes at earlier ages. However, our results demonstrate that the relationship between somatic and otolith growth can vary ontogenetically and differ between the sexes. This will limit the reliability of back-calculation of size at age in sex-changing species and the sex-specific back-calculations in gonochoristic species, 

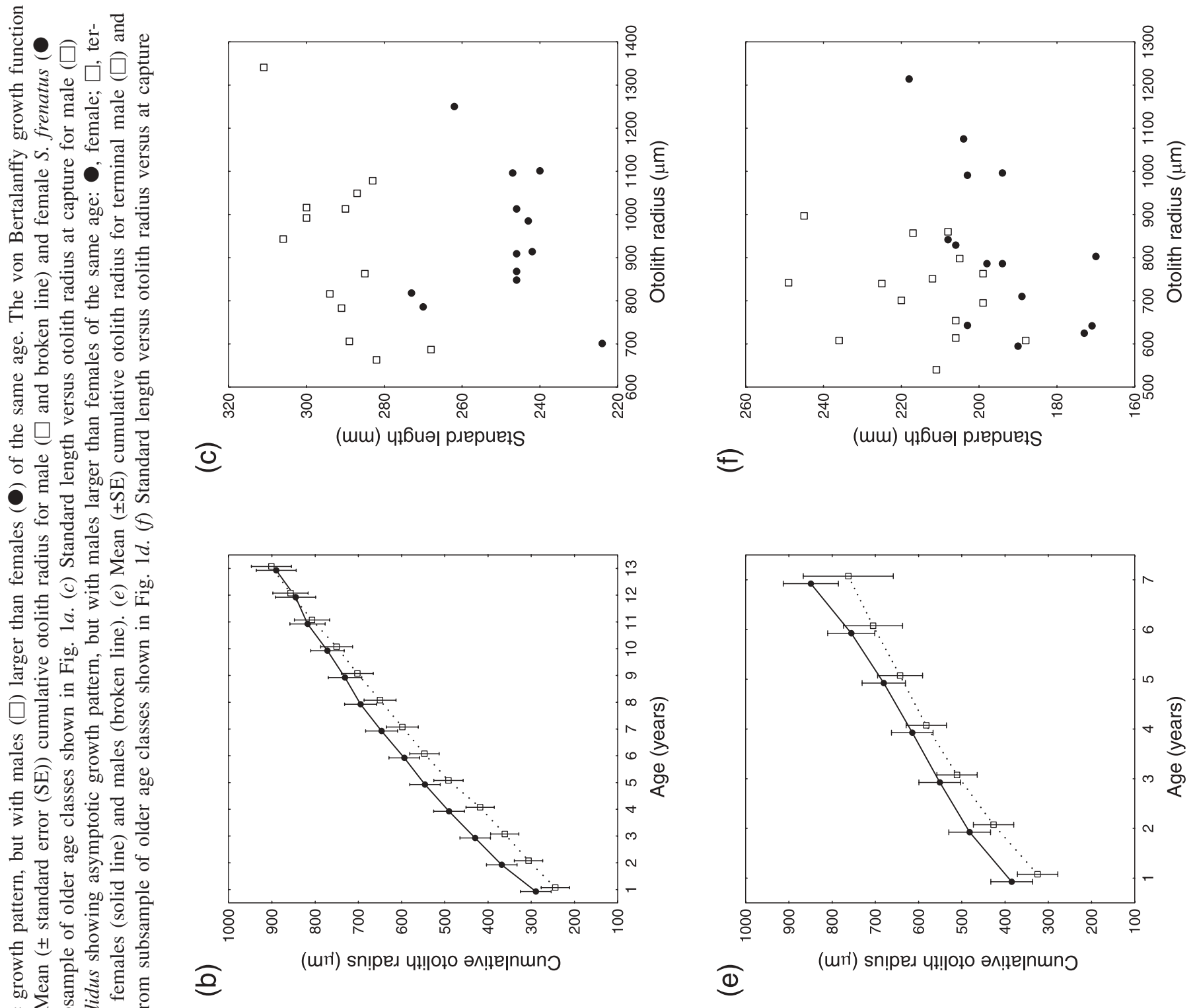



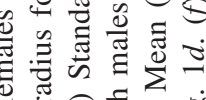

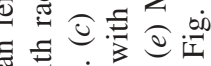

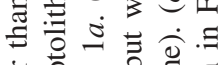

可



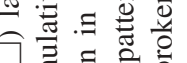

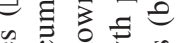

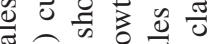

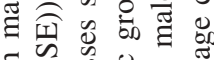

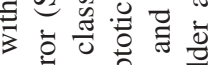

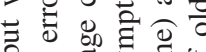

군

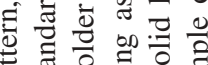

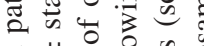

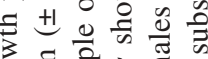

चี त्ञ

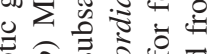

อำ

(uri) sn!̣ped 4!!!이 әк!!ฺ|nunว

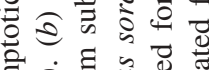

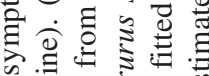

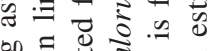

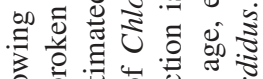

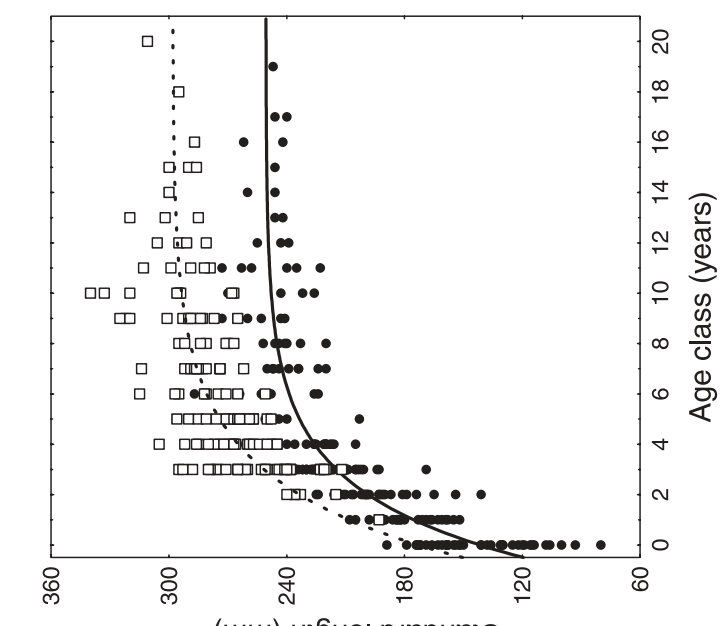

(6) (mm) чұбиә рдериетs

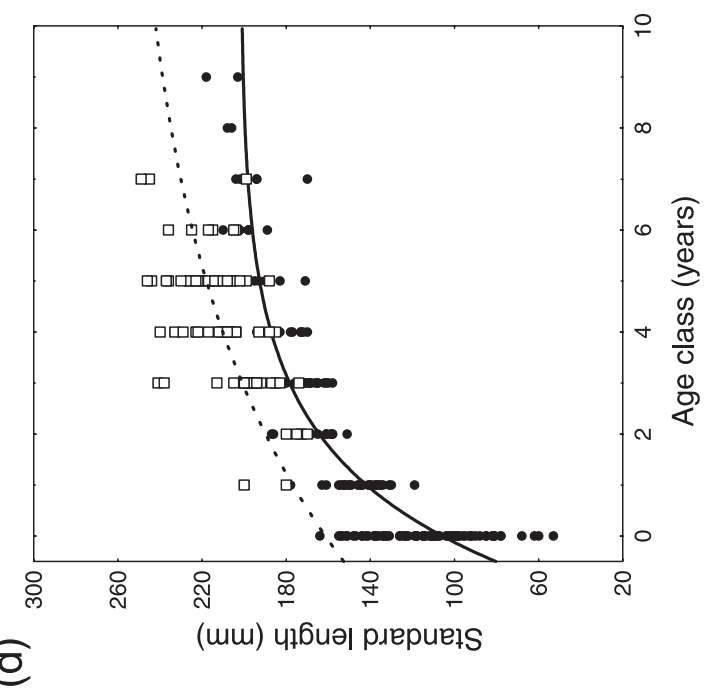

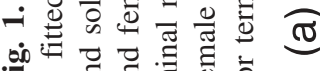


unless the precise relationship between otolith and somatic growth is known for each sex.

\section{Acknowledgements}

We thank staff at Lizard Island Research Station for help with the logistics of collecting samples. Collections were made while N.G. was supported by a Young Australian Award from the Queens Trust and a Lizard Island Doctoral Fellowship. We thank Steve Campana, Chris Francis, and an anonymous reviewer for suggestions on an earlier version of this paper that led to substantial changes and improvement. This research was supported by a James Cook University Merit Research grant to J.H.C., a James Cook University Prestige grant to J.H.C. and Mark McCormick, and an Australian Research Council Discovery grant to P.L.M. This research was conducted under permit G96/481 from the Great Barrier Reef Marine Park Authority.

\section{References}

Campana, S.E. 1990. How reliable are growth back-calculations based on otoliths? Can. J. Fish. Aquat. Sci. 47: 2219-2227.

Choat, J.H., Axe, L.M., and Lou, D.C. 1996. Growth and longevity in fishes of the family Scaridae. Mar. Ecol. Prog. Ser. 145: $33-41$.
Francis, R.I.C.C. 1990. Back-calculation of fish length: a critical review. J. Fish Biol. 36: 883-902.

Francis, R.C. 1992. Sexual lability in teleosts: developmental factors. Q. Rev. Biol. 67: 1-18.

Francis, R.C., and Barlow, G.W. 1993. Social control of primary sex differentiation in the Midas cichlid. Proc. Natl. Acad. Sci. 90: 10673 - 10675 .

Gust, N. 2004. Variation in the population biology of protogynous coral reef fishes over tens of kilometres. Can. J. Fish. Aquat. Sci. 61: 205-218.

Gust, N., Choat, J.H., and Ackerman, J.L. 2002. Demographic plasticity in tropical reef fishes. Mar. Biol. 140: 1039-1051.

Metcalfe, N.B., Huntingford, F.A., Graham, W.D., and Thorpe, J.E. 1989. Early social status and the development of life-history strategies in Atlantic salmon. Proc. R. Soc. Lond. 236: 7-19.

Morita, K., and Matsuishi, T. 2001. A new model of growth back-calculation incorporating age effect based on otoliths. Can. J. Fish. Aquat. Sci. 58: 1805-1811.

Reznick, D., Lindbeck, E., and Byrga, H. 1989. Slower growth results in larger otoliths: an experimental test with guppies (Poecilia reticulata). Can. J. Fish. Aquat. Sci. 46: 108-112.

Secor, D.H., and Dean, J.M. 1992. Comparison of otolith-based back-calculation methods to determine individual growth history of larval striped bass, Morone saxatilis. Can. J. Fish. Aquat. Sci. 49: $1439-1454$

Sirois, P., Lecomte, F., and Dodson, J.J. 1998. An otolith-based back-calculation method to account for time-varying growth rate in the rainbow smelt (Osmerus mordax) larvae. Can. J. Fish. Aquat. Sci. 55: 2662-2671. 